\title{
Hermeneutical Analysis of Narrative Approach in MacIntyre’s Moral Enquiry
}

\author{
Song Wei, Qin Mingli \\ Dalian University of Technology
}

\begin{abstract}
Alasdair MacIntyre identifies three types of moral research programs in a narrative approach in his works. In the view of hermeneutics, each of the three research programs has a narrative structure: Encyclopedia is a narrative structure with the belief in rational progress; Genealogy constructs its own narrative through the struggle with the past; Thomism tradition is a middle way of the previous two by pursuing truth from the history and particularity, thus avoiding the once-and-for-all rationality of Encyclopedia and the once-and-for-all relativism of genealogy. Narrative, as a living tradition, comprises of tradition-constituted one and tradition-constitutive one. The former is the given narrative we inherit from our predecessors, and the latter is the hermeneutical reinterpretation or reassessment of a tradition, thus showing the continuity among past, present, and future. Through the dialogical narrative especially according to Gadamer's I-Thou encounter, MacIntyre achieves a kind of traditional consensus between two traditions through a “common language” and "fusion of horizons.” MacIntyre’s theory is an account of the subjective condition of narrative quest for the truth, which is a good way to keep the integrity of thought in the modern alienation and deconstruction.
\end{abstract}

Keywords: MacIntyre, hermeneutics, narrative, moral enquiry

\section{Introduction}

Alasdair MacIntyre is one of the most prestigious moral philosophers in the English-speaking world. Apart from the unique investigation in virtue and rationality, Alasdair MacIntyre analyses three types of ethical research programs in his Three Rival Versions of Moral Enquiry and identifies that tradition is a better way than Encyclopedia and Genealogy to conduct moral enquiry. In the process of moral enquiry, MacIntyre adopts a narrative approach in the view of hermeneutics, pointing out that each of them emerges from different narratives about human life, human community, and human reason, and "the only criteria for success or failure in a human life as a whole are the criteria of success or failure in a narrated or to-be-narrated quest” (MacIntyre 2007, 219). This narrative approach serves as an opposition to scientific reason, in order to keep the integrity of thought in the modern alienation and deconstruction.

Song Wei, Ph.D. student, School of Humanities, Dalian University of Technology, lecturer of Dalian University of Foreign Languages, China; main research field: Hermeneutics and Ethics.

Qin Mingli, professor, School of Foreign Languages, Dalian University of Technology, China; main research field: Hermeneutics.

This paper is supported by National Social Science Fund Projects (11BWW003); Scientific Research General Project of Liaoning Provincial Education Department (W2015098); Scientific Research Youth Project of Dalian University of Foreign Languages (2014XJQN22). 


\section{Three Versions of Moral Enquiry}

\subsection{Narrative Structure of Encyclopedia}

Encyclopedia is a narrative structure with the belief in rational progress, and within this single framework knowledge is separate from belief and truth is considered as the relationship between knowledge and the world. This kind of narrative is a meta narrative, which doesn't permit the sensitivity to differences and the tolerance of incommensurability, and is a "truncate, oppress, and obliterate alternative forms of social life; they also set the stage for schism” (Lyotard 1999, XXIV-XXV). Encyclopedia is an ethical research program of modern liberal individualism, originating in thoughts of Descartes and Kant, in the belief of rational argumentation to reach a single and unitary conception about any one particular subject matter. Therefore, this encyclopedist view of reason is a typical Enlightenment project, which is epitomized as a historical, impersonal, universal, excluding all particular times and places, and "to succeed, rational inquiry requires freedom from allegiance to any community, religious or moral, with that partiality of standpoint that any such allegiance brings" (D’Andrea 2006, 349). The encyclopedist conception has a once-and-for-all character... and replaces orthodoxy with reason (McAdam 2011, 88). According to Gordon Graham, “This conception of rational inquiry understands the pursuit of truth and the acquisition of knowledge according to the model of compiling an encyclopedia. It is the conception... that the pursuit of understanding consists in the timeless, yet progressive accumulation of information” (Graham 2003, 27). Liberalism rejected the authority of tradition, with the belief that all rational people could agree on some objective and general arguments, but it failed in the definition of the universal rational principles it dogmatically asserts.

\subsection{Narrative Structure of Genealogy}

Genealogy constructs its own narrative through the struggle with the past, and arose as a rejection of Encyclopedia. Contrary to the encyclopedists' view, genealogists such as Nietzsche take a multiplicity of perspectives to assert a truth-from-a-point-of-view, and believe that there are no rules of rationality to obey. Genealogists believe that they liberate humanity from the deceptions of metaphysics and dogmatism, but in fact it turns out to be self-deceptive in the following two aspects (Lutz 2000, 91-93). First, genealogy cannot escape metaphysics and also depends on metaphysical presuppositions. If Nietzsche and other genealogists want to communicate their commitments in the form of rational arguments, then they have to appeal to impersonal and timeless rational standards. MacIntyre mentions that "This appeal to impersonal, timeless standards, so often taken for granted in the post-Enlightenment world by those who take themselves to have rejected metaphysics, is itself only to be understood adequately as a piece of metaphysics” (MacIntyre 1990, 45).

In making his or her sequence of strategies of masking and unmasking intelligible to him or herself, the genealogist has to ascribe to the genealogical self a continuity of deliberate purpose which can only be ascribe to a self not to be dissolved into masks and moments, a self which cannot but be conceived as more and other than its disguises and concealments and negotiations, a self which just insofar as it can adopt alternative perspectives is itself not perspectival, but persistent and substantial. (MacIntyre 1990, 54)

"Hence, once again, it seems to be the case that the intelligibility of genealogy requires beliefs and allegiances of a kind precluded by the genealogical stance” (MacIntyre 1990, 55). Second, if Genealogy intends to justify its claims and make itself become perpetuated as a research program, they have to adopt a dogmatic tone. Michel Foucault is a good example of genealogical research, but he also ended up speaking in an academic voice, 
Foucault himself became a professor of professor... ended up with nearly 15 years speaking ex cathedra from the college of France; but also that this inversion symbolizes Foucault's movement towards and final arrival at the plain academic style of the Histoire de la sexualite and the even plainer explanations offered in that wearisome multitude of interviews in which the academic deference evident in the questions in never rejected by Foucault in his answers. (MacIntyre 1990, 53)

Despite the huge difference between Encyclopedia and Genealogy, they also have something in common, which deeply influence their argumentation process. First, they both construct the philosophical history as one ranging from Socrates to the 19th century, but for Encyclopedia, this is the history of rational progress which is the inheritance and promotion of the reasoning concept and rational enquiry invented by Socrates, Plato, and Aristotle; for Genealogy, reason is the servant of power will and also tries to hide it. Therefore, Encyclopedia sees a progressed and unified history, and Genealogy sees a unified history full of distortion and repression, but they both see history as a unity.

\subsection{Narrative Structure of Thomism Tradition}

The third version of MacIntyre's moral enquiry is tradition, which is the "middle way" of the previous two unsatisfactory alternatives by pursuing truth from history and particularity. Narrative plays an essential role in avoiding the once-and-for-all rationality of Encyclopedia and the once-and-for-all relativism of genealogy. The core of MacIntyre's tradition is that the good life and the practices about the good life can only be developed through the collected wisdom of a tradition. And traditions in MacIntyre's works have different meanings. In Three Rival Versions of Moral Enquiry, tradition means the Aristotle-Thomistic metaphysical tradition, which turns to Plato, Aristotle, Augustine, and Thomas Aquinas. Meanwhile, MacIntyre argues that Encyclopedia and Genealogy are also traditions, because tradition is the true representative of moral enquiry and can exist in all of the moral traditions. All the past traditions can serve as the important sources for "understanding the strengths and weaknesses of a particular answer to a theological or philosophical question, which itself typically arose as a consequence of these differing sources being placed in juxtaposition with one another” (MacIntyre 1988, 206).

Aquinas is a principal figure in MacIntyre's narrative and he developed a role for tradition, and a systemic synthesis and a dialectical interplay between different authorities—Augustine and Aristotle—who are the main feature of Aquinas's moral enquiry. Through the description of Thomistic narrative and the introduction of Aquinas' concept of rationality and justice, MacIntyre illustrates his tradition-based moral enquiry,

what is clear nonetheless is that Aquinas account is only fully intelligible, let alone defensible, as it emerges from an extended and complex tradition of argument and conflict that included far more than Aristotle and Augustine. The notion of detaching it from that tradition and presenting its claims in terms of some alleged neutral criteria of a rationality, understood in independence of any tradition of practice and theorizing, makes no sense for it is an account of the criteria of rationality, and the part played by the virtues in the exercise of rationality, which itself emerges from and is justified in terms of the background of the traditions to which Aquinas made himself the heir. (MacIntyre 1988, 205)

\section{Narrative Tradition}

MacIntyre's theory is an account of the subjective condition of narrative quest for the truth. His moral enquiry has the characteristics of tradition-immanent and tradition-transcendent. On the one hand, everyone is involved in the pursuit with what we already have, which is called "fore-having" in the view of hermeneutics, and this includes our native language and culture, and its presuppositions. That means every philosophical position must be tradition immanent and tradition dependent. The history of philosophy is an account of story 
about the human's pursuit of truth. The questions both philosophers and common people encounter can change the view of human life and human action. On the other hand, the confirmation, emendation, and rejection of established moral theories must be based on the aims to discover the truth about human life and action. It's a pursuit of hermeneutical truth based on the fusion of horizon. In his moral theory, MacIntyre not only emphasizes the tradition-dependent feature of subjective rationality, but also strives to identify how the truth of things may influence the false forms of rationality, leading to the questions that cause changes. The truth of things can give rise to epistemological crises through the experience of contingent events, forcing challengers to reassess and to propose a more adequate account of the things. When the reconstruction is adequate enough, and the epistemological crisis is overcome, a new version may replace its predecessor in the tradition.

\subsection{Tradition-Constituted Narrative}

Tradition-constituted means tradition has the feature of historicity and particularity, and tradition is the given narrative we inherit from our predecessors. Human life has an innate narrative structure, because we are the co-authors of our life stories, and various aspects of one's life such as age, family background, location and physical and mental abilities all partly decide one's future direction of story. Likewise, tradition comes from a context of historical contingency. A particular community will always start with a given set of beliefs, practices, and institutions, and "A living tradition then is a historically extended, socially embodied argument" (MacIntyre 2007, 222). This narrative phenomenon of embedding is essential in two ways: First, the practice in present time is implanted in the larger history of tradition, and the practice is transmitted to us in an intelligible form; second, everyone's life is embedded in the larger and longer traditions through which our own lives can be understood. "Both moral reasoning and moral concepts are inherently historical artifacts requiring a certain social context for people to recognize and employ the relevant concepts in a clear, determinate way, and for their applications to be rationally defensible according to accepted standards" (Garcia 2003, 100). Past experience is not only the event that has happened, but also the premise of self-understanding, which in fact turns to Gadamer's structure of hermeneutical experience. Individuals are embedded in the shared social structure through our taking part in the constant change of these frameworks in which our own understanding is improved. There are two questions about it, which can be explained from the hermeneutical view (Thames 2011, 192-4).

The first question is how we can make sure that this change is an improvement rather than towards a worse and unauthentic understanding. In order to explain clearly how the modification takes place, it is necessary to mention Gadamer's hermeneutic circle. Everyone begins with a "fore-having"- "the background grasp of the language, our familiarity with the subject matter, and so forth, out of which we project the meaning of the text" (Thames 2011, 192). This projection goes against the existing experience and modifies the background, so that we can get a new meaning. And "understanding what is there" involves "working out this fore-projection, which is constantly revised in terms of what emerges as (one) penetrates into the meaning" (Gadamer 1989, 267). We are unable to enter the task of interpretation without the fore-having. But sometimes in the process of interpretation, our fore-having is not adequate to the subject matter. "All correct interpretation must be on guard against arbitrary fancies and the limitations imposed by imperceptible habits of thought, and it must direct its gaze 'on the things themselves'... throughout all the constant distractions that originate in the interpreter himself” (Gadamer 1989, 269). One goes into interpretation from fore-conception which is later replaced by more adequate ones. This insistent projection of new meaning makes up the process of understanding and interpretation. 
Understanding realizes its full potential only when the fore-meanings that it begins with are not arbitrary. Thus, it is quite right for the interpreter not to approach the text directly, relying solely on the fore-meaning already available to him, but rather explicitly to examine the legitimacy—i.e., the origin and validity—of the fore-meanings dwelling in him. (Gadamer 1989, 267)

The second question is how our background experience which constructs the initial projections can get modified "in terms of the things themselves," when we do not have the advantage of comparing the objective reality to our presupposition. This can be best explained through the nature of "experience"-an event that contradicts our engaged and unreflective coping of the everyday being in the world most of the time, it is not problematic for our dealing of the world. For example, when we use hammers, we do not notice the hammer itself and our movements. But when there is something wrong, these factors become "fore-sight" (in Gadamer's term), and if we want to know what goes wrong, we have to reconsider and reorganize them, the purpose of which is to make the fore-grounded elements become part of the background again, so that the task of building a desk, for example, can be resumed instead of only paying attention to the hammer. This can only be successful when the background information of hammer is modified "in terms of the things themselves" which means in terms of what is needed when dealing with things. And when the things themselves confirm the fore-meaning, we then have the true understanding of the things. Therefore, prejudice is not the thing we should avoid, but an essential part of our understanding.

\subsection{Tradition-Constitutive Narrative}

Tradition-constitutive narrative is a narrative that shows the continuity among past, present, and future, and the hermeneutical reinterpretation or reassessment of a tradition. It means that tradition is open and developing constantly. This opposes the idea of Hegel's “absolute knowledge," which underlines the universality and absoluteness of knowledge, so that knowledge is not likely to be modified. MacIntyre's constitutive tradition is anti-Hegelian, believing in the fallibility and modifiability of knowledge in particular circumstances. This is reflected in the argumentation and continuity of tradition.

Tradition is always in a debate, and "when a tradition is in good order it is always partially constituted by an argument about the goods the pursuit of which gives to that tradition its particular point and purpose" (MacIntyre 2007, 222). This conflict is revealed through epistemological crisis, which means in a particular belief there is a series of unsolvable problems and thus leads to the collapse of enquiry system. It occurs when a community with its own beliefs, institutions, and practices, comes into contact with another community with different beliefs, institutions, and practices, and faces some concept and practice difficulties which cannot be solved by their own standards. Thanks to the dialectical encounter between other communities, the community has the chance to take advantage of others' resources to solve their difficulties. Therefore, “a living tradition ten is a historically extended, socially embodied argument, and an argument precisely in part about the goods which constitute that tradition” (MacIntyre 2007, 222). MacIntyre's such concept of tradition contrasts sharply with conservative politics such as Edmund Burke who believes that tradition is opposite to reason, and the stability of tradition is opposite to its conflict. On the contrary, MacIntyre holds that if one tradition wants to survive, its constitutive parties have to argue and debate. Some elements of their earlier phases must be considered part of their continuing tradition. Through the contact with other communities, one tradition reevaluates and reformulates its elements hoping that the difficulties can be overcome. In this process, various transformations take place to produce an innovational change in the tradition. The innovational change may 
appear at different places in a continuum of possible change. However, such hermeneutical reinterpretation may only bring in less radical effects, and the greater and more profound changes may occur

in the community's material situation. When a community comes into contact with alternate communities, through commerce, war, migration, or contexts that affect its material well-being, its members may generate, either on their own or under some form of compulsion, significantly different versions of the beliefs, practices, and institutions that make up their traditions. (Jeffries 2000, 67)

And then the community has a new understanding of its conceptual and practical situation. The most important characteristic of a problem in a community's tradition lies in the fact that the problem drives its community to modify their understanding of the tradition with the relationship of the past and the present. No matter how major or how minor of the transformation, the community will understand its present tradition as superior to the past version.

A tradition also has continuity in spite of its constant evolution from earlier stages. According to MacIntyre, "traditions, when vital, embody continuities of conflict" (MacIntyre 2007, 222), and there is a core of beliefs, institutions, and practices which must keep consistent in the evolution of a tradition. The continuity of a tradition "incorporates the means through which a tradition overcomes the inevitable ruptures or crises that occur in its overall development and growth" (Jeffries 2000, 68). "A tradition is a tradition because it contains within itself some principle of continued existence through time. Therefore, some core belief must survive every modification of its belief set” (D’Andrea 2006, 330). Although the core belief of a tradition is changeable, it doesn't mean that a tradition cannot be defined. In some shared and core belief, the adherents of one tradition can establish some decisive elements which are the purpose and significance of debate in a tradition. If one tradition wants to survive, its internal conflict must be solved and its power of reason can be tested. In order to overcome the epistemological crisis, tradition must explain why the difficulty emerges, provide solutions, and expand its rational power, and maintain its continuities.

\section{Dialogical Narrative to Traditional Consensus}

Narrative as a use of language has the feature of dialogue, and the modification and fusion of horizons of one community with others is a matter of finding "a common language," one that allows the language to recede into the background and the subject matter to get our attention. To achieve the fusion of horizons needs communication of the background inherited from our history and tradition with the current particular situations. The revision of horizons can take place from dialectical experience in narrative, from which a kind of practical understanding emerges and thus the shared social horizons are modified. Here Gadamer's I-Thou encounter can be used to beset explain this kind of experience. There are three forms of I-Thou encounter-a mechanistic one, a subjectivistic one, and a dialogical one. The first two are inauthentic encounters, and only the third one is authentic. In the mechanistic relationship, Thou is considered as the object that covers typical behavior of human and can show the general law of human nature, according to which we can make predictions about others. In this sort of experience, Thou is a means to my end, the same as in Kant's formulation, and my relations to others is the operation of the general laws of human nature. In the second subjectivistic relationship, Thou itself is an end and a particular person, but I and Thou are atomistic, each expressing their own viewpoint striving for mutual understanding. Here, in order to understand the other, I have to bracket my own standpoint and get inside others' mind, which seems to fully recognize and respect others' point by not allowing my own viewpoints to influence how I understand others. I myself is extinguished. But in fact, it’s problematic because 
it presumes that one can understand others' claims without affecting one's own perspective, and the understanding is separate from what it means for myself. Both of the previous conceptions neglect the shared social network for I-Thou encounter. Only in the shared horizons can I and Thou be understood, and these horizons are constituted in and by language as "they contain conceptions of value and significance that stand beyond what we happen to pursue as biological creatures, conceptions of things as worthy of pursuit" (Thames 2011, 206). Therefore, I-Thou encounter must be hermeneutically dialogical. The virtuous person who shows phronesis also has to keep a dialogical relationship with the rest of world. In the dialogical I-Thou encounter, we can have a true understanding of normative standard which is natural in the world, the false prejudices can be corrected, and the background structure which is the basis of phronesis can be shaped and confirmed.

Through the dialogical narrative, MacIntyre achieves a kind of traditional consensus, and two traditions conduct a dialogue through a "common language." The adherents of tradition A learn the language of tradition $\mathrm{B}$ as a "second first language" and also learn its views in culture, morality, and intellect. Thomas Aquinas is the best example of a person who stands at the boundary of two cultures through speaking the language of two traditions-Augustinianism and Aristotelianism. The adherents of tradition A find that tradition B has the resources to solve their own epistemological crisis. To solve the epistemological crisis of tradition A, tradition B is to retell the story of how tradition A falls to the crisis and of how tradition B uses its resources to solve it, and the out-narration must accord with the standards of tradition A. In this sense, tradition B reconstructs a new narration of tradition A by providing a more adequate historical account of its successes and failures, and the two traditions get a "common ground" and "fusion of horizons."

\section{Conclusion}

Tradition-constituted and tradition-constitutive narrative can reply to the question unsolved by meta-ethics, that is, good people always do something they understand to be the best, but this understanding can only be acquired from their own experience, therefore, differences cannot be overcome by appealing to universal principles. Instead, the differences in a particular tradition can be conquered by the mutual understanding and critical reevaluation of opposite elements, and the understanding and evaluation in narrative serves as the judgment basis of moral principle. Of course, epistemological crisis does not occur frequently, and most of the time we are just like the prisoners in Plato's cave who will not challenge the shadows in front of them, because we don't have enough reasons to do so. We don't know what we don't know and thus are unable to pursue it. But when epistemological crisis really takes place, we cannot ignore it and cannot yield to it either. We should face it directly and try to solve this problem and enhance the explanatory abilities of the tradition. Tradition moves from the past to the future in a narrative way that has not yet been completed.

\section{Works Cited}

D’Andrea, Thomas D. Tradition, Rationality, and Virtue: The Thought of Alasdair MacIntyre. Aldershot: Shgate, 2006.

Gadamer, Hans Georg. Truth and Method. 2nd ed. Trans. J. Weinsheimer and D. G. Marshall. New York: Continuum, 1989.

Garcia, J. L. A. “Modern(ist) Moral Philosophy and MacIntyrean Critique.” Ed. Mark C. Murphy. Alasdair MacIntyre. Cambridge: Cambridge University Press, 2003.

Graham, Gordon. “MacIntyre on History and Philosophy.” Ed. Mark C. Murphy. Alasdair MacIntyre. Cambridge: Cambridge University Press, 2003. 
Jeffries, Paul Franklin. After MacIntyre: A Role for Tradition in Moral Philosophy. Minneapolis: University of Minnesota Press, 2000.

Lutz, Christopher Stephen. Tradition in the Ethics of Alasdair MacIntyre: Relativism, Thomism, and Philosophy. Washington D.C.: Catholic University of America, 2000.

Lyotard, Jean Francois. The Postmodern Condition: A Report on Knowledge. Trans. Geoff Bennington and Brian Massumi. Theory and History of Literature, Vol. 10. Minneapolis: University of Minnesota Press, 1999.

MacIntyre, Alasdair. After Virtue: A Study in Moral Theory. 3rd ed. Notre Dame: University of Notre Dame Press, 2007.

---. Three Rival Versions of Moral Enquiry. Notre Dame: University of Notre Dame Press, 1990.

---. Whose Justice? Which Rationality? Notre Dame: University of Notre Dame Press, 1988.

McAdam, Brian M. Narrative, Truth, and Relativism in the Ethics of Alasdair MacIntyre. Washington D.C.: Catholic University of America, 2011.

Thames, Bradley J. Historicity, Contingency and Virtue. Notre Dame: University of Notre Dame Press, 2011. 